\title{
Development of Engineering Management Education in China
}

\begin{abstract}
Engineering management (EM) is a new interdisciplinary field accompanying China's economic and social development. To have a systemic research of the present situation and future orientation on China's EM education, this paper compares the connotation of engineering and engineering management based on the gap of their differences at home and abroad, with gained causes between them. Then, this paper analyzes the training system of 35 authenticated universities with the program of engineering management, which had received the certification from the Engineering Management Assessment Committee for Higher Education Institutions under the Ministry of Housing and Urban-Rural Development of China by 2014. With a web survey of the present condition of engineering management education at these universities, the paper discusses the disciplinary attribution of engineering management. Through the above research, this paper concludes with three suggestions for the long-term development of engineering management education in China.
\end{abstract}

Keywords: engineering management, education, discipline, development, China

\section{Introduction}

Since the 1980s, China has gained great achievements in engineering construction and has built a large number of projects with worldwide attention, showing our excellence in construction. However, there was a great waste of resources because of lag in management level. As we know, the major of engineering management (EM) in China has experienced a progress over 20 years since its establishment in 1998, which has supplied a large number of professionals for the national engineering construction

Manuscript received May 29, 2015; accepted September 7, 2015

Chuan-jun Zheng $(\varangle)$, Hu Cheng

Southeast University, Nanjing 210096, China

Email: zcjfafu@seu.edu.cn industry and has promoted the development of EM discipline with a relatively complete education system. But, ambiguous orientation of discipline, less practical training, poor faculties and obvious differences on teaching levels among universities seriously restricted our demand of compound, export-oriented and pioneering talents engaging in modern engineering management with the progress of new industrialization (The Research Group of the Chinese Academy of Engineering, 2010a, b). Meanwhile, there was a lack of theoretical research and indigenous innovation in large-scale construction because of many foreign theories and means introduced to EM, which resulted in the gap between theory and practice. Whether the future engineering manager can successfully complete the major social and historical missions embedded in engineering or not will depend on present education quality of EM. Therefore, based on national strategies and social requirements, this research will helpful to China's sustainable development by thinking of EM education's discipline development, education system, and development strategies.

\section{Connotation of engineering and EM}

Throughout the history of human development, engineering activities have profoundly changed the production and life of the human world, which bridges between humanity and its environment. In the face of environmental pollution, energy shortage and information explosion, it is also becoming important to understand engineering and humans in engineering - EM. Nowadays, the domain and connotation of engineering have changed continually with technological progress and social development. Therefore, to clarify the engineering and EM's connotation is the basis of knowing EM education correctly.

\subsection{Connotations of engineering}

Encyclopedia Britannica interpreted engineering as a special technology which applied scientific principles to optimally transform natural resources into structure, 
machinery, products, systems, and processes for a human's welfare. The National Academy of Engineering of the United States (NAE, USA) held that there was a variety of interpretations, which referred to scientific applications as well as design in limited resources. To sum up, there is consistent recognition of engineering in the Western countries. Namely, it is to transform scientific principles into creative activities for new products by the engineers' teamwork. So, it is the engineers that have a very extensive understanding of engineering and of any specialized technical field as an engineering discipline. For example, the NAE set up corresponding secondary and tertiary areas on economics and management in every department. This is an important reflection on the complete understanding of engineering.

Likewise, Cihai (literally rendered, word-sea; freely rendered, an encyclopedic dictionary of the words), the Chinese e-dictionary gives two explanations: (a) general term of various disciplines formed by the application of natural science principles in the department of industry and agriculture production; (b) specific construction and construction projects. The former has the same understanding as foreign engineering disciplines in a broad sense, and the latter refers to architectural engineering with narrow definition. Meanwhile, this difference exists in domestic scholars. Tan and Li (2007) thought that the purpose of engineering was to construct the facilities, installations or conceptual systems to transform natural resource for one-time development/construction or human welfare, which used scientific principles and integrated various technologies in limited time, space, and resources and formed a goal-oriented process with integration of human power and other resources. But He and Wang (2008) held that it was the integrated activities, which used science and technology to create things or change the object's characteristics for human's survival and development. Therefore, both of them agree on its scientific application, purposiveness, process and systemization, toward on the idea of large-scale engineering. However, in comparison, the former is with more connotations of project, and the latter emphasizes on materiality.

To sum up, there is a difference of the connotations of engineering at home and abroad. The consistent understanding of it formed because of a long interaction among the engineering industry, enterprise and engineering education abroad. This is the idea of large-scale engineering with its scientific, technical and practical integration (Chen, 2011). In contrast, there is a generalized concept of it in China such as the "Five Ones Engineering" and "Vegetable Basket Engineering". Moreover, due to the differences of the stages of development, and of the engineering understood in different stages, it is difficult to agree on one connotation. From the perspective of the EM discipline, it refers to the complex process for humanity's particular demands on scientific applications as well as creative activities, which are needed to complete an integrated system through teamwork.

\subsection{Connotations of EM}

American Society for Engineering Management (ASEM) interpreted EM as a science and art to plan, organize, allocate resource, monitor and control in technical activities. The consultant project of the CAE - "Research on the Development of EM Science in China" - had a similar understanding, which takes EM as achieving the desired objectives by effective use of planning, decisionmaking, organization, command, coordination, and control. Both of them are broadly defined and embedded with a concept of general management. In 2000, the CAE established the division of EM and gave it a clear interpretation as follows: (a) management in the implementation of major projects; (b) important and complex new products, devices and equipment, and management in the development, manufacture and production process; (c) management of major technological innovation, alteration, transformation and internationalization; (d) management and research of major layout and strategic development involved in industry, engineering and technology. Therefore, this definition is the idea of large-scale EM based on national need, with focus on its complexity and importance, but China's EM practices are mainly on construction management. EM is a multi-dimensional concept, which involves the state, departments, industries, enterprises and projects in vertical direction and spans over different disciplines and related industries in a horizontal direction. Moreover, there is difference and a lack of consistency in its connotations among industries, disciplines and majors. The involved discipline is the branch of scientific system based on teaching and research and the major in education refers to academic categories.

EM differed from general management in its systematic, comprehensive and complex nature (Tan \& Li, 2007). It focuses on both management and technology principles of engineering, or management science of engineering. During the process of human cognition, the researched objects of nature science and technology, engineering, industry and society form a chain (He \& Wang, 2008). Therefore, it has obvious technical integration and industrial correlation, with involvement in construction, transportation and water conservancy projects, etc. Now, China has established the Master of Engineering Management (MEM) degree to supply for the demanded of specialized technical management skills. This is different from a Master of Public Administration (MPA) degree and Master of Business Management (MBA) degree (Wang, Yang, \& Gao, 2011; Zhang, Wang, Zou, \& Li, 2014). Moreover, project management originally from the construction industry has extended to all professions and trades, becoming a set of general management techniques 
and methods. The Master of Project Management (MPM) degree serves this purpose. Generally speaking, all engineering projects require management. Therefore, it has obvious difference from general management; the only similarity is in management functions themselves (see Table 1).

\section{Higher education system of China' s EM}

The educational management and the development of universities is the basis of its discipline system. The corresponding professional education system directly embodies the level of maturity in a particular discipline. EM discipline in universities directly corresponds to the major of EM. Therefore, the training system and universities with this specialty in China can reflect a full view of its education system.

\subsection{Specialty of EM in Chinese universities}

Presently, China has established a complete system from undergraduate to doctor candidate in EM, which covers both academic degrees and professional degrees. It is a major attributed to the first-level discipline, Management Science and Engineering (MSE). However, the establishment of the post-graduate degree is complex because of its interdisciplinary characteristics and the restricted education resources in some universities (see Table 2). For example, some universities put it in first-level discipline, TechnoEconomics and Management (TM) and some in Civil Engineering Construction and Management (CECM). Neither is a part of MSE.

Therefore, the EM degree involves engineering and management, which embodies its compound features. It includes both academic and professional degrees, covering all levels from bachelor to doctoral degrees. It also involves MSE, Business Administration (BA) and the other engineering majors such as Civil Engineering (CE) and Architecture and Civil Engineering (ACE) in postgraduate education. According to the surveyed 84 universities with recruitment of MEM by CAE, the establishment of EM/EM direction in MSE and TM were approximately $50 \%$ and $30 \%$ respectively, and the minority of them were engineering majors such as $\mathrm{CE}$, Hydraulic engineering etc. (The Research Group of the Chinese Academy of Engineering, 2010a, b). A professional degree at the postgraduate level requires prior qualifications such as a

Table 1

Comparison of EM and General Management

\begin{tabular}{|c|c|c|c|c|}
\hline Managed object & Discipline & Level & Professional degree & Feature \\
\hline $\begin{array}{l}\text { Government/non- } \\
\text { governmental } \\
\text { organization }\end{array}$ & Public administration & Macro & MPA & Scientific administration of public policies and affairs \\
\hline Enterprise & Business management & Meso & MBA & $\begin{array}{c}\text { Daily management of continuous operation and general business } \\
\text { management }\end{array}$ \\
\hline Engineering & EM & $\begin{array}{l}\text { Macro, meso, and } \\
\text { micro }\end{array}$ & MEM & $\begin{array}{c}\text { Integrated management of technology, focus on particular technical } \\
\text { industry }\end{array}$ \\
\hline Project & Project management & Micro & MPM & $\begin{array}{c}\text { Management of one-off activities with limited resource, general } \\
\text { management methods and means }\end{array}$ \\
\hline
\end{tabular}

Table 2

Higher Education System of EM

\begin{tabular}{|c|c|c|c|c|c|c|}
\hline Discipline class & $\begin{array}{c}\text { First-level discipline/ } \\
\text { Domain }\end{array}$ & $\mathrm{PhD}$ & Master & Undergraduate & Degree category & Remarks \\
\hline $\begin{array}{l}\text { Management/ } \\
\text { Engineering }\end{array}$ & MSE & MSE & MSE & $\begin{array}{c}\text { EM/ engineering } \\
\text { cost }\end{array}$ & Academic & Main origin of students in EM \\
\hline Management & BA & TM & TM & EM & & \\
\hline Engineering & $\mathrm{CE}$ & CECM & CECM & $\mathrm{CE} / \mathrm{EM}$ & & \\
\hline \multirow[t]{2}{*}{ Engineering } & Engineering & $\ldots$ & $\mathrm{ACE}$ & ... & Professional & Focus on civil engineering \\
\hline & & $\begin{array}{l}\text { Doctor of engineer- } \\
\text { ing }\end{array}$ & $\ldots$ & $\ldots$ & & $\begin{array}{l}\text { Emphasis on management in } \\
\text { technical industry }\end{array}$ \\
\hline \multirow[t]{2}{*}{ Management } & Project & $\ldots$ & $\mathrm{PM}$ & $\ldots$ & & $\begin{array}{l}\text { General management for var- } \\
\text { ious industries }\end{array}$ \\
\hline & Engineering & $\ldots$ & MEM & $\ldots$ & & $\begin{array}{l}\text { Emphasis on management in } \\
\text { technical industry }\end{array}$ \\
\hline
\end{tabular}


bachelor degree in Science or Engineering or EM. A postgraduate degree may only follow a bachelor in EM because of the need for prerequisites and entrance exams in the same course of study. In general, all universities with a CE specialty offer an EM masters degree in ACE and PM. Presently, the Doctor of Engineering program is to cultivate advanced talents of technology and engineering innovation, which only focuses on electronic \& information, biology \& medicine, energy \& environmental protection and advanced manufacturing. Therefore, based on the idea of large-scale engineering, MEM focuses on extensive domains and mainly focuses on CE management. China has established a relatively complete cultivation system of EM in vertical and horizontal directions. However, professional degrees in EM are relatively extensive, and an academic degree of EM is mainly on CE.

\subsection{Undergraduate programs of EM in Chinese universities}

Presently, there are nearly 400 universities with undergraduate programs in EM. According to the list of certified universities by the Ministry of China Housing and UrbanRural Development by 2014, there is an analysis based the detailed information on these school websites (see Figure 1, Figure 2, Figure 3, and Figure 4).
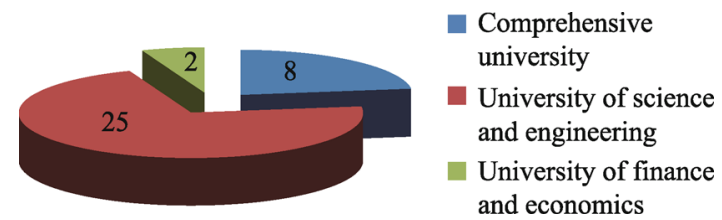

Figure 1. Distribution of university type.

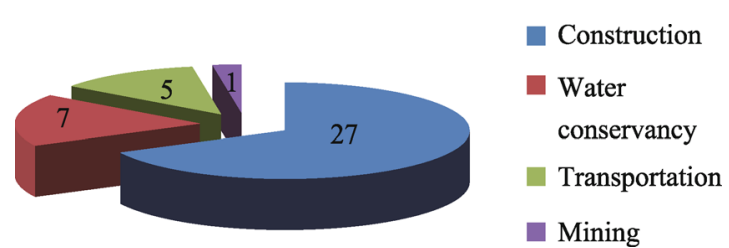

Figure 2. Involved industry of EM.

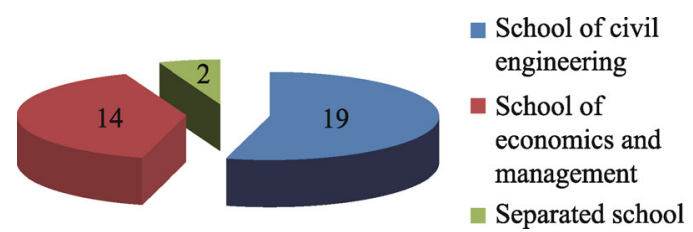

Figure 3. Schools of study.

Figure 1 depicts the distribution of university types. There were 8 comprehensive universities $(22.86 \%)$ with

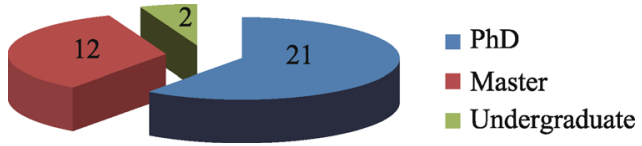

Figure 4. Level of degree.

undergraduate programs in EM, 25 universities of science and technology $(71.43 \%)$ and 2 universities of finance and economics $(5.71 \%)$. The former two types of universities accounted for $94.29 \%$ of the investigated universities, and only the minority of university of finance and economics opened this major. Thus, EM is the management of engineering technology, and it requires a foundation of engineering background.

Figure 2 depicts the industry feature of universities with EM. There were 27 universities $(77.14 \%)$ mainly on construction, $7(20.00 \%)$ on hydraulic engineering, 5 $(14.29 \%)$ on transportation, and 1 on mining (2.86\%). Among them, there were 3 universities both on construction and hydraulic engineering, 1 both on construction and transportation, and 1 both on transportation and hydraulic engineering. Therefore, China's EM mainly focuses on the management of industrial and civil buildings, and all of them focus on the management of wide civil engineering. Therefore, $\mathrm{CE}$ dominates the field of research and practice of EM.

Figure 3 depicts the schools of study with EM. There were 19 universities $(54.29 \%)$ with EM in the School of Civil Engineering, $14(40.00 \%)$ in School of Economics and Management, and 2 (5.71\%) in the Separated School with EM and other relational majors. Therefore, EM is different from technical majors such as Civil Engineering and General Management, whose discipline body of knowledge displays a compound feature of technology and management.

Figure 4 depicts the category of degree with EM in surveyed universities. There were 21 universities (60.00\%) with doctoral programs, $12(34.29 \%)$ with master programs, and $2(5.71 \%)$ only with undergraduate programs. So $94.29 \%$ of the certified universities can provide postgra duate programs in EM. Therefore, these universities have a high educational level with relatively better teaching resources and conditions. Putting them in the view of the universities nationwide, in terms of the educational level, EM programs well form a pyramid structure.

Overall, the 35 certified universities greatly display the present condition of China's EM education, although they only account for one-eleventh of universities with EM. It differs from the other management degrees, which consist of integrated management of technology in a particular industry, not simply technology plus management. Although Chinese EM education differs greatly in the background of universities, they show diversity as well as centrality, with $\mathrm{CE}$ primarily serving the construction industry. 


\section{Reflection of discipline attribution in EM}

As the expansion of applied domains in EM, there were scholars who appealed to strengthen its status and promote it to become a first-level discipline in the first China Engineering Management Forum (2007). As a young discipline, it affects the input and output of engineering industry. Its orientation should consider the present situation with certain perspective.

\subsection{Thinking of its attribution to MSE}

Presently, there are six majors in the undergraduate professional directory of MSE in higher education, including management science, information management and information system, EM, real estate development and management, engineering cost and a specialty of confidential management. However, there is no subordinate discipline of MSE in the postgraduate directory and discipline. Due to its combination of liberal arts and science, and with a large span between theory and practice, MSE involves various universities of the synthesizing type, science and technology, agriculture and forestry, teachertraining and finance \& economics. This may easily cause orientation differences and ignore the engineering basics. According to statistics, the above reasons lead to an excellent rate of only $22 \%$ in Chinese EM , and $66.3 \%$ of colleges with EM was under the average level (The Research Group of the Chinese Academy of Engineering, 2010a, b). Meanwhile, EM has technology integration and industry correlation, which is different from the other majors in MSE. Because of these reasons, some colleges label EM as an engineering discipline. Therefore, MSE cannot cover EM. This causes a lack of a unified category and management and affects the consistency of its discipline basis and domains.

Moreover, MSE tends to quantitative research and micro research, but the other affiliated directions of it attach more importance on mathematical models and computer technology with a focus on general management. Due to its main field in construction industry, the features of fixed product and flow production make quantitative research and micro research difficult to realize. As an application discipline, computer and information technology is just a tool, whose theories originate from a summary of EM activities and practical experiences. Therefore, it is easy to cause a gap between EM theory and practice according to the academic criteria of MSE. This is harmful to long-term development of the EM discipline and the engineering industry. In addition, there is an embarrassment in EM attributing to engineering discipline because $\mathrm{CE}$ focuses on tests with desired results by data analysis and EM is more concerned with individuals and their behaviors in engineering with mainly qualitative research. Therefore, its affiliation to MSE ignores inherent uniqueness and affects the development of the EM discipline.
4.2 Thinking of its independence to be a first-level discipline

The GB/T13745-2009 "Discipline Classification \& Code" clearly defines the qualification of a discipline as follows: (a) the formed theory system and special methods; (b) the emergence of relevant group of scientists; (c) the establishment and effective activities of research institutions, teaching units and academic community; (d) the publication of relevant monographs and publications.

By 1999, the majority of 22 members in the Council of the Academies of Engineering and Technological Sciences (CAETS) had developed several relevant departments of EM. Meanwhile, the Accreditation Board of Engineering and Technology (ABET) formally accepted EM as a subject with an independent degree in 1997. Moreover, ASEM and Institute of Electrical and Electronics Engineers (IEEE) set up the EM branch early. Therefore, there is consistent agreement on the EM discipline abroad based on coherent connotation of engineering and EM. In fact, the CAE had recognized and established the academic status of the EM discipline because of the faculty of EM in 2000. Now, there are nearly 400 colleges and universities with an undergraduate program of EM and 40 universities with a $\mathrm{PhD}$ program in China. This has formed a complete education system for EM education. Meanwhile, the China Engineering Management Forum has been held yearly since 2007, and has established the related society and industry organization such as Architectural Society of China-Construction Management Research Sector (ASCCMRS), China Construction Industry Association-Engineering Management Branch and China International Contractors Association, etc. In addition, the registered professional qualification system with integration to EM has been established for practical workers with complete channels from professional education to industry practice. Therefore, EM has formed an academic community on all levels.

EM is a discipline concerning the application of methods of engineering science and management science with efficient integration to achieve optimal engineering benefits (He, Chen, \& Hong, 2005). Its research was on management principles of special technology integration, in which existed an obvious interaction between theory and practice with extensive domains (He, Wang, \& Wang, 2009). It differs from industrial engineering, essentially in the PM and BA. From the view of professional degree, MEM focuses on general management ability based on a particular technological industry; MPM focuses on knowledge learning and ability training on projects with adaption to all industries; Master of Industrial Engineering Studies on large-scale industrial production and social economic systems, focusing on efficiency of the workshop production and application of mathematical methods, and mainly for manufacturing industry; MBA is a general education of comprehensive business management which stresses on 
general ability of BA (He et al., 2009; Zhang et al., 2014). Therefore, the ideas and methods of general management can't be used in EM practice directly because the combined general management theory and particular technology require abstracts and testing in real engineering projects.

As China becomes more urbanized, acquiring the status of the national economic pillar industry, the construction industry has experienced a continuous increase as the main field of EM. According to the survey in 2013, the construction industry added value accounting for $6.86 \%$ of GDP with an increase of $0.03 \%$ over the previous year, and an upward trend on national investment in fixed assets, the number of employees in construction and the whole society construction added value (Department of Planning, Finance and Foreign Affairs of the Ministry of Housing and Urban \& Rural Development, 2014). The construction industry provides the best platform for the Chinese EM staff as a special production department on engineering construction. Meanwhile, there are so many fields requiring organic combination of special technology and scientific management as the development of industrialization. Therefore, making EM an independent discipline will prove to accomplish its long-term development.

\section{Suggestion of EM education in China}

As the challenges of humanity increase, and with the growing complexity of science and technology and expanded actions of engineering activities, China is in urgent need of compound talents for the scientific management of specialized technology. Presently, China's economic transformation and social reform provides a great opportunity for the development of EM education. However, the existing problems restrict its development. It is therefore necessary to promote its greater role in future engineering activities for humanity, which should meet the Chinese scenarios and the trend of international engineering education.

5.1 Adapting to the trend of large-scale engineering concept and distinguishing academic degree from professional degree

The idea of large-scale engineering is a return to engineering education in practice, which is similar to the "Excellent Engineer Education and Training Program" with focus on engineering practice and innovation. However, China's EM is generally CE management in the construction industry because engineering construction projects provide the material basis for all industries. This is obvious in the academic degree of EM education, which is the same as the authenticated program of EM by American Council for Construction Education. In contrast, China's MEM can attract undergraduate students from various subject backgrounds, which can integrate into the authenticated program of EM by ASEM with a focus on an unspecific industry. Therefore, the colleges with EM can promote a differentiation on EM education according to their advantages and resources. Sois suitable to expand the academic degree of EM to construction project management, and professional degree of EM to large-scale management. Both consider the present and future requirements for China's EM education.

5.2 To make EM a first-level discipline and improve its disciplinary theory and specialty education

Presently, engineering activities play a greater role in national and social development because of large-scale construction, with its expanding application domains. Therefore, making EM's separation from MSE and becoming a first-level discipline can ensure a systemic and normative body of discipline knowledge, which can provide the opportunity to form a practical discipline with comprehensive competitive power. The ambiguity of its discipline attribution and the differences in major orientation among universities can be easily resolved with consistence understanding, providing a solid basis of disciplinary theory establishment and improvement in educational level. Meanwhile, the professionals of the theory circle and practice circle can discuss the EM's development issues on the shared platform when promoting it to be a first-level discipline. It is helpful to integrate international trends of EM education with the drive in the development of the Chinese EM theory system.

5.3 To strengthen the alliance of production, teaching and research and enhance the professional society's role

Presently, the Chinese government is making a change toward "small government and big service". The professional society organizations will play a more positive role in EM education. EM is an applied discipline with a focus on engineering practice and close coordination among colleges, enterprise and industry, and can close the gap between theory and practice. This can effectively improve the educational level of EM. In fact, there is a promotion of engineering education certification in China, but is limited by internal authentication within the education system due to a lack of guidance concerning the social needs of professionals. In comparison, the European and American professional society such as the RICS (Royal Institution of Chartered Surveyors) and CIOB (Chartered Institute of Building) of United Kingdom conducted an early intervention of the relevant college curriculum arrangements and assessed its response level for professional ability, further establishing the lifelong learning mechanism with specialized education, practice education and continuing education though the pre-established criteria of basic ability, core capabilities and specialist abilities. Therefore, the professional society can bridge the gap between college and enterprise. This is necessary to establish an EM 
discipline system and address uneven levels in EM education.

\section{Conclusions}

Presently, the rapid development of China's economy and society provides a good opportunity for EM education. However, the present inconsistencies in discipline foundations, great differences in educational levels and ignorance in practical training have seriously affected the development of EM discipline. Therefore, the adaptation and transformation of the development ideas, development modes and guiding ideology under the guide of "Scientific Development Concept" has become more important to EM. To improve EM education in China, it is right to consider the integration of large-scale engineering and pay attention to engineering practice based on Chinese scenarios of EM, which require collective efforts among industry, enterprise and colleges for sustainable development of Chinese EM education.

\section{References}

Chen, J. (2011). Reform on curriculum system of engineering management specialty based on large-scale engineering idea. Journal of Architectural Education in Institutes of Higher Learning, (5), 100104
Department of Planning, Finance and Foreign Affairs of the Ministry of Housing and Urban \& Rural Development. (2014). A statistic analysis of the development of China's construction industry in 2013. Journal of Engineering Management, 28, 1-10

He, J., Chen, X., \& Hong, K. (2005). On engineering management. Engineering and Science, (10), 5-10

He, J., \& Wang, M. (2008). Philosophical thinking on engineering and engineering management. Engineering and Science, (3), 9-12

He, J., Wang, M., \& Wang, Q. (2009). Theory parising and system construction for engineering management. Science \& Technology Progress and Policy, (21), 1-4

Tan, Z., \& Li, H. (2007). Resurveying of engineering and engineering management: a series of discussion on engineering management. Coal Economics Research, (4), 48-49

The Research Group of the Chinese Academy of Engineering. (2010a). A research of engineering management education in China in the process of new industrialization (part a). Higher Engineering Education, (4), 1-9

The Research Group of the Chinese Academy of Engineering. (2010b). A research of engineering management education in China in the process of new industrialization (part b). Higher Engineering Education, (5), 12-21

Wang, X., Yang, Q., \& Gao, R. (2011). Professional degree education of master of engineering management in foreign countries and experience to be learned by China. Science \& Technology Progress and Policy, (13), 140-143

Zhang, Y., Wang, M., Zou, D., \& Li, X. (2014). Research on present education situation of master of engineering management and countermeasure. Science \& Technology Progress and Policy, (11), $119-122$ 